\title{
Educação como instrumento de formação de consciências: construção do conhecimento na busca por equidade
}

Education as an instrument for consciousness: Construction of knowledge in the search for equity

\section{Marcella Coelho Marques \\ celacm52@hotmail.com}

Graduanda em Direito pela PUC-Rio

\section{Resumo}

O presente artigo objetiva analisar as questões sociais mais latentes atualmente, localizando-as dentro do amplo contexto no qual o tema da educação se insere. Para tal, foi realizado um levantamento bibliográfico com algumas das principais referências relativas ao estudo da educação. Como resultado, constatou-se a importância da construção de uma consciência do eu, do outro e do meio na formação acadêmica.

Palavras-chave: consciência; igualdade; justiça social; inclusão.

\begin{abstract}
This article aims to analyze the most latent social issues currently, locating them within the broad context in which the theme of education is inserted. To this end, a bibliographical survey was carried out, with some of the main references relating to the study of education. As a result, the importance of building an consciousness of the self, the other and the environment in academic training was found.
\end{abstract}

Keywords: consciousness; equality; social justice; inclusion. 
MARQUES, Marcella Coelho. Educação como instrumento de formação de consciências: construção do conhecimento na busca por equidade.

\section{Introdução}

No século XVIII, surgem as estruturas que irão reger a educação contemporânea. A crença de que a alfabetização e a difusão da cultura são os pilares do processo educativo, embora importantes até hoje, é ultrapassada mediante as transformações que moldam nossa percepção da realidade. Realidade essa que se abre como um leque para questões como a percepção do eu, o reconhecimento do outro e o entendimento do meio no qual estamos inseridos.

Objetivando fomentar a construção dessas consciências, fez-se um levantamento bibliográfico com algumas das mais relevantes referências no estudo da educação contemporânea, de maneira a analisar de que forma tal posicionamento de conscientização é essencial para a construção de uma base sólida e libertadora no âmbito da produção e do compartilhamento do conhecimento.

Segundo Paulo Freire ensina: “A educação problematizadora faz, assim, um esforço permanente através do qual os homens vão percebendo, criticamente, como estão sendo no mundo com que e em que se acham” (Freire, 1987a, p.41). A problemática é que tal percepção crítica e, até mesmo, esse esforço permanente esbarram em obstáculos que vão desde uma educação rígida e fechada, perpetuando-se até os dias de hoje, à dificuldade de execução dessas ideias de forma igualitária para todos. É importante ressaltar que tal frase foi dita no início do século passado e, apesar de haver ocorrido avanços, traços de uma educação autoritária permanecem existindo.

Apesar dos vestígios autoritários que ainda persistem, é com esperança que seguimos caminhando para uma sociedade em que a pluralidade seja reconhecida como natural. No entanto, para que isso seja alcançado, faz-se necessário haver pluralidade também em nossa forma de pensar, de agir e de compartilhar o conhecimento. Nesse sentido, um processo educativo que vise a formação de indivíduos capazes de perceberem-se enquanto seres sociais, porém também individualizados, deve ser pautado na construção de uma consciência baseada em três pilares: do eu, do outro e do meio de que fazemos parte. Ou seja: consciência de quem somos, das interações que fazemos, do ambiente no qual nos inserimos e do lugar que ocupamos dentro dele.

Uma formação educativa que priorize em sua essência a descoberta enquanto ser individual, incentivando a construção de um olhar crítico, poderá se desdobrar em outras descobertas com potencial de transformação e liberdade, funcionando ativamente como instrumento para desconstrução de padrões arbitrários e opressores, ainda enraizados DIGNIDADE RE-VISTA | ISSN2525-698X| 2021 | V. VIII | N. 13 |Pacto Educativo Global: a busca por ressignificar a educação. Pastoral Universitária Anchieta PUC-RIO. 
MARQUES, Marcella Coelho. Educação como instrumento de formação de consciências: construção do conhecimento na busca por equidade.

socialmente. Tendo em vista as inúmeras realidades e vivências plurais existentes, somente a construção de uma base educativa que valorize a diversidade e seja pautada em promover o abarcamento de todos igualmente poderia funcionar como instrumento de libertação.

A percepção crítica refere-se ao reconhecimento, também, do lugar que ocupamos socialmente, das diferenças de meios de transposição de obstáculos, e dos privilégios inerentes para a sua transposição, tornando possível que nos enxerguemos como indivíduos pertencentes a um determinado grupo, beneficiado ou marginalizado pelo Estado.

Nesse sentido, a educação, vista como processo que objetiva o estímulo ao pensamento crítico, por meio da formação de indivíduos questionadores da realidade, torna possível o pensamento de uma realidade mais igualitária, em que os cidadãos saibam com maior segurança quais são os direitos que possuem, podendo, assim, exigir que sejam eles cumpridos.

Dentro desse contexto, no qual se busca a construção de uma sociedade mais igual, se torna imprescindível que todo o processo educativo seja pautado, desde sua base, em uma filosofia apegada ao respeito, ao reconhecimento das diferenças e à empatia. Entretanto, evidencia-se que, para adquirir a igualdade efetiva, não se pode esquecer das dívidas históricas com grupos menos privilegiados, relegando-os à simplória meritocracia. Faz-se necessário conferir tratamento desigual aos desiguais, de modo a alcançar, de fato, igualdade no plano material e de acessibilidade à educação de qualidade. Atentar e instigar essa percepção significa estar a par das transformações e urgências sociais das quais o Brasil carece, pois estará capacitando indivíduos a se tornarem cidadãos que, além de informados, estarão aptos a analisarem criticamente a realidade ao seu redor e a confrontá-la quando necessário.

Construir um projeto de educação baseado na formação de uma consciência social a respeito da realidade, através de um pensamento crítico, é também construir a possibilidade de acesso a uma perspectiva de futuro igualitária, sendo essencial para que possamos alcançar o contexto de justiça social que tanto almejamos.

\section{Consciência do Eu}

Desde o momento em que formamos uma concepção de presente, passado e futuro, e iniciamos um processo consciente de trazer nossas memórias à tona, nos lembramos da época em que frequentávamos o ambiente escolar. O processo educativo se inicia muito cedo, fazendo parte dos primórdios de nossas lembranças relacionadas à infância, época de início da formação da percepção de nós mesmos e do mundo ao nosso redor.

DIGNIDADE RE-VISTA | ISSN2525-698X| 2021 | V. VIII | N. 13 |Pacto Educativo Global: a busca por ressignificar a educação. Pastoral Universitária Anchieta PUC-RIO. 
MARQUES, Marcella Coelho. Educação como instrumento de formação de consciências: construção do conhecimento na busca por equidade.

Dentro dessa perspectiva, as experiências que vivenciamos no ambiente escolar carregam enorme importância, tendo em vista ser na escola onde criamos nossos primeiros vínculos sociais afetivos, sejam eles positivos ou negativos, e onde aprendemos a compartilhar os ambientes e seus recursos, vivenciando pela primeira vez o sentido de coletividade. Além disso, é também o local onde experienciamos o primeiro contato com o conhecimento de maneira metódica. $\mathrm{O}$ ambiente escolar, de qualquer maneira irá propiciar efeitos sociais involuntários, os quais são fruto direto da interação inerente a esse ambiente, que ocorrerá independentemente da existência de interesse em promovê-la.

A questão que se coloca a respeito da formação de consciência do "eu" sob a perspectiva do processo educativo é que o desenvolvimento de tal consciência seja incentivado e, principalmente, viabilizado, dentro do ambiente educativo, a partir de um esforço focado nesse objetivo; através do oferecimento de disciplinas aos alunos que visem a construção do autocontrole, da capacidade de praticar atenção plena e de busca por autoconhecimento.

A existência também de um suporte pedagógico individualizado, de um conhecimento que abranja as diversidades históricas e de ancestralidades existentes, valorizando-as e reconhecendo a realidade plural ao nosso entorno, são iniciativas que beneficiam a construção de uma subjetividade individualizada e saudável. Para tanto, o ambiente educacional deve ser hígido, contribuindo para que todos sintam-se acolhidos e confortáveis para se expandirem e expressarem, enquanto seres em formação. Além disso, deve ser um ambiente atento às pluralidades existentes, de modo a estabelecer, desde o início, o compromisso em abandonar padrões construídos socialmente que buscam determinar como devemos ser, o que devemos fazer e como devemos pensar.

Em semelhante raciocínio, Aníbal Quijano expõe de que maneira a formação da subjetividade está fortemente relacionada ao espaço, dentro do qual exacerbamos nosso senso crítico e o quanto isso influencia na busca por igualdade social enquanto necessidade:

A individualização das pessoas só adquire seu sentido nesse contexto, a necessidade de um foro próprio para pensar, para duvidar, para decidir; a liberdade individual, em suma, contra as adscrições sociais fixadas e em consequência a necessidade de igualdade social entre os indivíduos. (Quijano, 2005, p.125)

Dentro desse contexto, torna-se essencial que ocorra uma reorganização a respeito do conhecimento basal que é compartilhado, para que se torne um conhecimento que valorize a 
MARQUES, Marcella Coelho. Educação como instrumento de formação de consciências: construção do conhecimento na busca por equidade.

diversidade de fato. Devendo resgatar historicamente os povos, as culturas e as ancestralidades, apagadas em função de um projeto de educação hegemônico. Ainda conforme Quijano:

\begin{abstract}
A incorporação de tão diversas e heterogêneas histórias culturais a um único mundo dominado pela Europa, significou para esse mundo uma configuração cultural, intelectual, em suma intersubjetiva, equivalente à articulação de todas as formas de controle do trabalho em torno do capital, para estabelecer o capitalismo mundial. Com efeito, todas as experiências, histórias, recursos e produtos culturais terminaram também articulados numa só ordem cultural global em torno da hegemonia europeia ou ocidental. Em outras palavras, como parte do novo padrão de poder mundial, a Europa também concentrou sob sua hegemonia o controle de todas as formas de controle da subjetividade, da cultura, e em especial do conhecimento, da produção do conhecimento. (2005a, p.121)
\end{abstract}

A constatação de que hegemonia e diversidade são ideais paralelos é essencial. Em igual sentido, a formação de nossa identidade, de nossa noção de representatividade e de pertencimento são estágios de autoconhecimento e interação social saudável, cujo alcance não se alinha com um processo educativo inflexível e limitante. Em direção contrária à limitação, a década atual é marcada pela possibilidade rápida e simples de acesso à informações e conhecimentos através da internet, e as diferentes perspectivas que dimensiona moldam as maneiras de construção do pensamento e, consequentemente, também da realidade. Quanto mais destoante o conteúdo educativo apresentado for do cotidiano fugaz e espetaculoso que vivenciamos na atual era digital, maior será a dificuldade do estudante em "linkar" o conhecimento compartilhado.

Dentro desse contexto, em que são apresentadas milhares de opções em formas de cliques, o caminho para a construção de uma consciência sólida a respeito de si torna-se ainda mais desafiador, tendo em vista que a facilidade de acesso e a quantidade de informação disponível no mundo virtual não correspondem necessariamente à existência de qualidade do que é consumido. Nesse sentido, um método de educação engessado e hierarquizado, frente a um mundo cada vez mais fluido e conectado digitalmente, torna-se, acima de tudo, ineficaz. Não há meios de controlar o que os alunos estarão consumindo quando imersos digitalmente, porém, o educador pode contribuir à medida em que valorize a importância da construção de uma identidade própria e genuína, através da qual realmente se enxerguem, frente à extravagante quantidade de referências aleatórias ofertadas on-line, funcionando como ponte entre o interesse pela busca por um conteúdo de qualidade e o indivíduo.

DIGNIDADE RE-VISTA | ISSN2525-698X| 2021 | V. VIII | N. 13 |Pacto Educativo Global: a busca por ressignificar a educação. Pastoral Universitária Anchieta PUC-RIO. 
MARQUES, Marcella Coelho. Educação como instrumento de formação de consciências: construção do conhecimento na busca por equidade.

Milton Santos, enquanto ensinava sobre a força da solidariedade em meio ao contexto da globalização, já preconizava o quanto a alienação com relação a si, ao outro e ao meio, enfraquece os indivíduos em sua essência, humanamente distinta: “A força da alienação vem dessa fragilidade dos indivíduos, quando apenas conseguem identificar o que os separa e não o que os une" (Santos, 2013, p. 93).

Portanto, é inquestionável a urgência que temos à nossa frente, de abrir espaço dentro do ambiente educacional para a construção de identidades de maneira positiva e respeitosa. Priorizar o desenvolvimento do ser enquanto subjetivo e fluido poderá fazer com que existamos enquanto seres sociais, aptos aos direitos e deveres da vida civil, sem que tenhamos o desejo íntimo de pertencer a um mundo cuja realidade espelhe a nossa própria.

\section{Consciência do Outro}

O conceito de Colonialidade é analisado por Aníbal Quijano como o padrão de poder criado pelo colonizador para controlar a subjetividade dos povos colonizados (Quijano, 2005), de maneira que o monopólio exercido sob a ótica colonial, a respeito da produção do conhecimento, é utilizado hoje ainda como instrumento de apagamento de povos e culturas. Dentro dessa perspectiva, é necessário compreender que o processo educativo é responsável também pela construção dos padrões psíquicos e pela visão subjetiva que iremos construir, não só sobre nós mesmos, mas também a respeito do outro.

A maneira como estabelecemos conexões com o próximo é diretamente influenciada pelas narrativas que são criadas a respeito de sua proveniência, de modo que um conhecimento marcado por estereótipos racistas estigmatiza pessoas negras a imagens negativas de subserviência e inadequação. Partindo desse contexto, enquanto crianças brancas crescem cercadas de imagens positivas, em meio a uma atmosfera intensa de representatividade, à medida em que ocupam os espaços de poder, crianças negras são constantemente estigmatizadas pelo racismo estrutural que vivenciam. A existência de uma representatividade que abarque as minorias, logo, é fundamental para viabilizar a construção de um ambiente educacional equitativo, em que a formação de uma consciência positiva a respeito de si e do outro seja possível.

A reprogramação do conteúdo transmitido dentro dos ambientes educacionais é urgente para que se coloque um freio nas colonialidades ainda existentes nos dias de hoje, que permanecem reproduzindo massivamente formas dinâmicas de violência na atualidade e que DIGNIDADE RE-VISTA | ISSN2525-698X| 2021 | V. VIII | N. 13 |Pacto Educativo Global: a busca por ressignificar a educação. Pastoral Universitária Anchieta PUC-RIO. 
MARQUES, Marcella Coelho. Educação como instrumento de formação de consciências: construção do conhecimento na busca por equidade.

significam também violências ao futuro, tendo em vista que aniquilam possibilidades e aspirações. Além disso, a capacitação e diálogo dos educadores de maneira a formar um pensamento homogêneo, que tenha como foco o respeito na convivência com as diferenças, é essencial para eliminar condutas preconceituosas no ambiente escolar. O respeito e a inclusão das minorias, seja por questão de classe, de gênero, religião, seja de etnia, precisa ser considerado requisito básico do conteúdo a ser compartilhado como conhecimento nos ambientes educacionais. Desse modo, garante-se desde cedo uma construção de consciência empática a respeito do outro.

Em igual raciocínio, o ambiente educacional, enquanto instituição, necessita ser também embebido de consciência, de maneira a respeitar os indivíduos em sua totalidade, atentando para particularidades específicas, vinculadas, por exemplo, às pessoas com deficiência. À narrativa social que pensa o corpo das pessoas com deficiência como menos humano, menos capaz, menos qualificado ou suficiente, damos o nome de capacitismo. A percepção da necessidade de desconstrução de um modelo de ambiente educacional que seja capacitista e da subsequente reconfiguração desse ambiente, de maneira a torná-lo equitativo, se faz completamente necessária.

A carência de políticas públicas e iniciativas que deem conta da inserção das pessoas com deficiência em espaços que elas normalmente não ocupam ainda é uma realidade que precisa ser subvertida, sob pena de novas gerações crescerem fadadas a ausência de representatividade e, consequentemente, de perspectiva. Seja através do exercício de uma atividade profissional seja através da oportunidade de busca pelo conhecimento, a inserção, de fato, da pessoa com deficiência no ambiente educacional significa inseri-la de acordo com sua capacidade e não de acordo com sua deficiência.

A ausência de representatividade possui como um dos efeitos mais danosos o aniquilamento de sonhos. Tal fato distorce os parâmetros de realidade e a visão que temos não só de nós mesmos, como também das pessoas que nos cercam, prejudicando a construção da autoestima, do amor-próprio e da empatia. A partir do momento que nos é negada a identificação, nos é negada a capacidade de sonhar. Sendo assim, é imprescindível que a educação se atente à pluralidade, enquanto essência humana, de modo que possa contribuir diretamente para a ocorrência de uma ruptura entre o sistema educacional e as narrativas de viés colonial, homogeneizador e inflexível. 


\section{Consciência do Meio}

A consciência do meio em que estamos inseridos reflete a importância necessária do estudante em reconhecer o meio como um campo social e ecológico. Com uma crise de atenção, refletida diretamente nos jovens, imersos em uma modernidade líquida que caracteriza os tempos atuais, como classifica Zygmunt Bauman, muitas vezes é difícil desconstruir a "redoma de vidro" na qual muitos estudantes estão inseridos. Isso dificulta o entendimento das mazelas e disparidades existentes no campo social, nem dá importância a uma mentalidade de desenvolvimento sustentável na conscientização ambiental.

Através da percepção das diferentes pluralidades, vivências e, consequentemente, necessidades que nos permeiam como indivíduos, torna-se inegável a constatação de que qualquer ambiente coletivo deve ser pautado no ideal de respeito às diferenças e na promoção da igualdade. Faz-se necessário o abandono de uma perspectiva homogênea do ambiente educacional, que durante décadas busca determinar o perfil dos indivíduos que terão acesso à educação e daqueles que ficarão completamente à margem dela. Essa metodologia discriminatória resulta em uma educação seletiva e elitista, comprometida em sua essência, e que não possui outra perspectiva de produção de resultado a não ser o de perpetuação das desigualdades e dos mecanismos de manutenção de injustiças sociais.

Dentro desse contexto, como conseguir alcançar todos através da educação, sem que nenhum grupo seja marginalizado? Primeiramente, faz-se necessária uma filosofia de ensino adequada à realidade que vivenciamos de fato: repleta de diferenças. Além disso, é também essencial que ocorra o abandono de teorias superficiais e negligentes, como por exemplo, a da existência da meritocracia. Essa deve ser interpretada como mito, que distorce a realidade, fazendo emergir um sentimento de culpa pela falta de êxito em indivíduos que são, na verdade, vítimas da marginalização produzida pelo próprio Estado. Seguindo tal raciocínio, torna-se necessário também que ocorra a implementação de projetos e políticas públicas que visem garantir a entrada e a permanência de alunos que ocupem algum nível de vulnerabilidade social ou, ainda, que vivenciem mais de uma condição de vulnerabilidade, de maneira a tornar o ambiente educacional mais próximo da realidade, ou seja, mais diverso.

A reconfiguração desse ambiente poderá resultar também no enriquecimento das possibilidades de troca de conhecimento. Retirará de um lugar marginalizado milhares de indivíduos, de maneira a devolver o alcance de possibilidades que lhes foi roubado ao se colocar em prática um processo educativo produtor de injustiças.

DIGNIDADE RE-VISTA | ISSN2525-698X| 2021 | V. VIII | N. 13 |Pacto Educativo Global: a busca por ressignificar a educação. Pastoral Universitária Anchieta PUC-RIO. 
MARQUES, Marcella Coelho. Educação como instrumento de formação de consciências: construção do conhecimento na busca por equidade.

Ainda sob o prisma da conscientização do meio, é impossível não refletir sobre o ciclo degenerativo que vem sendo imposto ao meio ambiente. O jovem hoje em dia se depara com o paradoxo: o crescente aumento de manifestações e conferências na tentativa de se preservar a biosfera e seu equilíbrio, ao mesmo tempo em que muitos países ainda descumprem acordos e pactos firmados. A visão mesquinha de que a natureza seja apenas um recurso utilitário, fica ainda mais evidente no crescente desmatamento e queimadas que ocorrem na Amazônia e no Pantanal, escancarando a voragem do capitalismo extrativista, como nos explica Boaventura de Souza Santos:

Tal como acontece com a democracia, só uma consciência e uma ação ecológica robusta, anticapitalista, pode fazer frente com êxito à voragem do capitalismo extrativista. Ao "ecologismo dos ricos", é preciso contrapor o "ecologismo dos pobres" baseado numa economia política não dominada pelo fetichismo do crescimento infinito e do consumismo individualista e, antes, baseada nas ideias de reciprocidade, solidariedade, complementaridade vigentes tanto nas relações humanas como nas relações entre humanos e a natureza. (2016, p. 141)

É nessa disputa entre avanço econômico e preservação do meio ambiente que aparentemente percebe-se que o lado mais fraco, no atual cenário, é a natureza. Embora as repercussões desse descaso já sejam alarmantes, ainda parece não ser suficientemente desesperador para provocar mudanças imediatas e rígidas no combate ao desmatamento. Nunca foram tão necessários o ensino e a prática de medidas sustentáveis que visem a preservação do meio em que vivemos. A razão entre produção, gasto e preservação ainda não encontrou um denominador comum.

O enfrentamento e tomada de consciência a esse respeito não envolve somente a noção de que essa questão é inadiável. Envolve, mais do que isso, um engajamento ativo desde os primeiros anos de vida, tornando o aluno do amanhã comprometido em conferir ao meio ambiente a importância inegociável que esse, de fato, possui.

\section{Conclusão}

Embora a educação e a pedagogia venham sendo amplamente discutidas no âmbito teórico desde o século passado, a ideologia mercantilista que rege nossa sociedade hoje em dia é, de certa forma, uma barreira nessa transição do plano teórico para o executivo. O retrato do processo educativo reflete as características da realidade atual: formação tecnicista que prioriza o mercado de trabalho, segregadora e ineficiente no que se refere à construção de um ser DIGNIDADE RE-VISTA | ISSN2525-698X| 2021 | V. VIII | N. 13 |Pacto Educativo Global: a busca por ressignificar a educação. Pastoral Universitária Anchieta PUC-RIO. 
MARQUES, Marcella Coelho. Educação como instrumento de formação de consciências: construção do conhecimento na busca por equidade.

humano seguro psicologicamente, consciente para com o outro e engajado no meio em que está inserido. A falta de pragmatismo na execução de novas ideias a respeito de como educar demonstra que o problema não é a falta de ideias, mas a falta de interesse em executá-las. $\mathrm{O}$ que traz a reflexão da inacessibilidade de grupos menos privilegiados: consequência histórica de uma sociedade doente ou efeito premeditado?

É necessário que a educação amplie seu espectro de abordagem, de forma a abraçar o aluno não somente no conteúdo técnico, mas na formação de um indivíduo capaz de exercer um pensamento crítico que o possibilite de se reconhecer/identificar no mundo em que vive, a ter empatia às diferentes realidades que o cercam, e a permitir-se a liberdade de assimilar que é um ser em constante transformação. Como demonstrado neste trabalho, a valorização e incorporação da consciência do eu, do outro e do meio como pilares do processo educativo possibilitarão que ocorra uma ressignificação a respeito de como o conhecimento pode ser produzido, pensado e compartilhado.

Não há escassez de exemplos que podem ser seguidos. A consciência e plenitude do eu podem ser encorajadas com aulas de atenção plena, respaldo psicológico profissional nas instituições e a presença de conselheiros pedagógicos individualizados, que possam assessorar e orientar os alunos em formação. A consciência do outro pode ser aprimorada primeiramente quando a acessibilidade for mais justa e contemple grupos menos favorecidos de maneira a termos uma representatividade mais fidedigna da realidade. Além disso, essa consciência pode ser construída através de mais trabalhos de campo sociais, e na readequação dos conteúdos, que são majoritariamente eurocêntricos. Já na consciência do meio, cabem ao educador e educando mais trabalhos de campo ambiental, principalmente no Brasil, rico em fauna e flora e pobre na sua conservação; e ensino que valorize também noções de economia básica e constituição/formação das leis.

Outra consequência relevante ocorre também na desconstrução do lugar que tipicamente o educador ocupa, como sendo o único agente ativo do processo de compartilhamento do conhecimento, estando o aluno, dentro dessa configuração, no polo passivo. O aluno, mais empoderado de suas consciências, também se torna agente ativo nessa troca de conhecimento, logo mais eficiente. Como ensina Paulo Freire:

Desta maneira, o educador já não é o que apensas educa, mas o que, enquanto educa, é educado, em diálogo com o educando que, ao ser educado, também educa. Ambos, assim, se tornam sujeitos do processo em que crescem juntos e em que os "argumentos de autoridade" já não valem. Em que, para ser-se, DIGNIDADE RE-VISTA | ISSN2525-698X| 2021 | V. VIII | N. 13 |Pacto Educativo Global: a busca por ressignificar a educação. Pastoral Universitária Anchieta PUC-RIO. 
MARQUES, Marcella Coelho. Educação como instrumento de formação de consciências: construção do conhecimento na busca por equidade.

funcionalmente, autoridade, se necessita de estar sendo com as liberdades e não contra elas. (1987, p.39).

Talvez a otimização nesse diálogo, entre educando e educador, consiga com o tempo desconstruir a passividade e a inércia mental que ainda engessam as variadas formas de troca de conhecimento. A sintonia fina entre atuação ativa e passiva em todos os agentes educacionais deve zelar, principalmente, pela independência mental e autonomia de raciocínio, desencorajando a absorção inócua de conhecimento. O resultado final seria, com esperança, ter em mãos uma ferramenta robusta de criação de narrativas próprias e de entendimento dos espaços ao redor. 
MARQUES, Marcella Coelho. Educação como instrumento de formação de consciências: construção do conhecimento na busca por equidade.

\section{Referências bibliográficas}

BAUMAN, Zygmunt. Modernidade Líquida. Rio de Janeiro: Jorge Zahar, 2001.

FREIRE, Paulo. Pedagogia do Oprimido. Rio de Janeiro: Paz e Terra, 1987.

QUIJANO, Aníbal. Colonialidade do poder, Eurocentrismo e América Latina. In: LANDER, Edgardo. A colonialidade do saber: eurocentrismo e ciências sociais. Perspectivas Latinoamericanas. Buenos Aires: Consejo Latinoamericano de Ciencias Sociales, 2005.

SANTOS, Boaventura de Souza. A difícil democracia: reinventar as esquerdas. São Paulo: Boitempo, 2016.

SANTOS, Milton. O espaço da cidadania e outras reflexões. Brasília: Fundação Ulysses Guimarães, 2013. 